\title{
PENGUMPULAN BIJI DAN PERKECAMBAHANNYA SELAMA SATU PERIODE JATUHNYA BIJI DARI POHON INDUKNYA DAN PENUNDAAN PENGECAMBAHAN BIJI Aquilaria microcarpa Baill. DI PERSEMAIAN (Seed Collection and Germination During One Period of Seed Fall from Its Mother Tree and Delay of Seed Germination of Aquilaria microcarpa Baill. at Nursery)*
}

\author{
Oleh/By: \\ Rayan \\ Balai Besar Penelitian Dipterokarpa \\ Jl. A. Wahab Syahrani, Sempaja - Samarinda Telp. (0541) 206364 Fax. (0541) 742298 \\ e-mail : bpk-smd@samarinda.org Website : www.bp2k.go.id, Samarinda \\ * Diterima : 17 Maret 2008; Disetujui : 30 September 2009
}

\begin{abstract}
The aim of this study was to find out germination quality in relation to time seed falling sequences (the first study) and delay of seed germination (the second one). The seeds derived from mother trees in Sempaja Arboretum, while germination study was conducted at the nursery of the Dipterocarps Research Center of Samarinda. The completely randomized design with factorial $2 \times 7$ was used for the first study. The first factor was germination medium consisting of sand without endomycorrhiza $\left(E_{0}\right)$ and sand with endomycorrhiza $\left(E_{1}\right)$. The second factor was time interval of seed collection consisting of $P_{1}$ (seeds collected on the $3^{\text {rd }}$ day of seed fall period), $P_{2}$ (the $5^{\text {th }}$ day), $P_{3}$ (the $7^{\text {th }}$ day), $P_{4}$ (those on $10^{\text {th }}$ day), $P_{5}$ (the $13^{\text {rd }}$ day), $P_{6}$ (the $17^{\text {th }}$ day, and $P_{7}$ (the $24^{\text {th }}$ day). The completely randomized design was used for the second study. The treatments were $P W_{0}$ (direct seed germination), $P W_{1}$ (10 day-delay seed germination, $P W_{2}$ (12 day-delay), and $\mathrm{PW}_{3}$ (17 day-delay). The results of the study showed that the average germination of Aquilaria microcarpa Baill was $74.76 \%$. Germination of seeds in $E_{0}$ was $75.55 \%$, while that in $E_{1}$ was $73.79 \%$, but the difference was not statistically significant. The P treatments were highly significantly different, however, the following test (LSD) indicated that the treatments of $P_{6}(60.55 \%), P_{7}(64.44 \%), P_{5}(70.00 \%)$, and $P_{1}(71.11 \%)$ were not significantly different. These treatments resulted bad germination quality which was less than the average of overall germination i.e. $74.76 \%$. Good germination quality values were more than $74.76 \%$ which were from the treatments of $\mathrm{P}_{4}(79.45 \%), P_{2}$ (87.78\%), and $P_{3}(90.00 \%)$. Result of seed germination delay showed that $P W_{0}(88.89 \%)$ was highly significantly different compared to $P W_{1}(31.11 \%), P W_{2}(25.56 \%)$, and $P W_{3}(15.56 \%)$, while $P W_{1}, P W_{2}$, and $P W_{3}$ were not significantly different.
\end{abstract}

Keywords: Germination, mother tree, Aquilaria microcarpa Baill.

\begin{abstract}
ABSTRAK
Penelitian ini bertujuan untuk mendapatkan informasi tentang kualitas perkecambahan biji jenis Aquilaria microcarpa Baill. berdasarkan periode jatuhnya biji. Rancangan percobaan yang digunakan adalah rancangan acak lengkap pola faktorial 2 x 7. Faktor pertama adalah media kecambah dengan perlakuan media pasir tanpa endomikoriza $\left(E_{0}\right)$, media pasir dengan endomikoriza $\left(E_{1}\right)$. Faktor kedua interval waktu pengumpulan biji dengan perlakuan $\mathrm{P}_{1}$ (pengumpulan biji hari ke-3), $\mathrm{P}_{2}$ (pengumpulan biji hari ke-5), $\mathrm{P}_{3}$ (pengumpulan biji hari ke-7), $\mathrm{P}_{4}$ (pengumpulan biji hari ke-10), $\mathrm{P}_{5}$ (pengumpulan biji hari ke-13), $\mathrm{P}_{6}$ (pengumpulan biji hari ke17), dan $P_{7}$ (pengumpulan biji hari ke-24); dan penundaan pengecambahan biji menggunakan rancangan acak lengkap dengan perlakuan $\mathrm{PW}_{0}$ (biji yang langsung dikecambahkan), $\mathrm{PW}_{1}$ (pengecambahan biji tertunda 10 hari), $\mathrm{PW}_{2}$ (pengecambahan biji tertunda 12 hari), dan $\mathrm{PW}_{3}$ (pengecambahan biji tertunda 17 hari). Pengumpulan biji dilaksanakan pada pohon induk yang tumbuh di Arboretum Sempaja, sedangkan pengecambahan biji dilakukan di persemaian Balai Besar Penelitian Dipterokarpa. Hasil yang diperoleh secara keseluruhan rata-rata daya kecambah biji jenis $A$. microcarpa sebesar 74,76\%. Perlakuan $\mathrm{E}_{0}$ menghasilkan rata-rata daya kecambah $75,55 \%$ sedangkan $E_{1} 73,79 \%$, dan setelah diuji secara statistik tidak berbeda nyata. Perlakuan interval waktu pengumpulan biji berbeda sangat nyata terhadap rata-rata daya kecambahnya. Setelah diuji lebih lanjut perlakuan $\mathrm{P}_{6}, \mathrm{P}_{7}, \mathrm{P}_{5}$, dan $\mathrm{P}_{1}$ dengan rata-rata daya kecambah berturutturut 60,55\%, 64,44\%, 70\%, dan 71,11\%, tidak berbeda nyata. Perlakuan ini menghasilkan biji yang bermutu kurang baik, karena biji-biji tersebut rata-rata daya kecambahnya lebih kecil dari rata-rata keseluruhan daya kecambah selama satu periode jatuhnya biji dari pohon induknya yaitu 74,76\%. Biji-biji yang berkualitas
\end{abstract}


lebih baik adalah biji yang rata-rata daya kecambahnya lebih besar dari 74,76 \%, di antaranya biji-biji yang diperoleh dengan perlakuan $\mathrm{P}_{4}$ dengan rata-rata daya kecambah yang dihasilkan sebesar 79,45\%, $\mathrm{P}_{2}$ (87,78\%), dan $\mathrm{P}_{3}(90 \%)$. Hasil perlakuan penundaan pengecambahan biji dari perlakuan $\mathrm{PW}_{0}$, disusul $\mathrm{PW}_{1}$, $\mathrm{PW}_{2}$, dan $\mathrm{PW}_{3}$ dicapai rata-rata daya kecambah berturut-turut 88,89\%, 31,11\%, 25,56\%, 15,56\%, dan setelah diuji dengan statistik menunjukkan bahwa pengaruh perlakuan $\mathrm{PW}_{0}$ dibandingkan dengan $\mathrm{PW}_{1}, \mathrm{PW}_{2}$, dan $\mathrm{PW}_{3}$ berbeda sangat nyata tetapi perlakuan antara $\mathrm{PW}_{1}, \mathrm{PW}_{2}$, dan $\mathrm{PW}_{3}$ tidak berbeda nyata.

Kata kunci: Perkecambahan, pohon induk, Aquilaria microcarpa Baill.

\section{PENDAHULUAN}

Hutan Kalimantan kaya akan jenis-jenis pohon, di antaranya yang mempunyai nilai ekonomi tinggi, baik berupa kayu maupun Hasil Hutan Bukan Kayu (HHBK) dan banyak dipanen juga merupakan jenis andalan setempat Kalimantan. Salah satu HHBK dari jenis tumbuhan penghasil gaharu adalah Aquilaria micricarpa Baill.

Gaharu adalah produk dari jenis pohon tertentu berupa gumpalan akibat terkena penyakit, warnanya coklat sampai kehitam-hitaman dan jika dibakar menimbulkan bau harum. Secara ekonomis harganya mahal dan banyak kegunaannya di antaranya untuk parfum (wewangian), dupa, dan obat-obatan (Schuitemaker, 1988). Kulit batang tumbuhan ini dapat digunakan sebagai bahan anyaman seperti tas, topi, keranjang, dan tali (Heyne, 1987; Sidiyasa dan Suharti, 1987; Tantra, 1981). Salah satu di antaranya adalah $A$. microcarpa yang tumbuh secara alami di hutan-hutan Kalimantan. Harga yang mahal menyebabkan jenis ini banyak diburu oleh masyarakat yang mengakibatkan semakin menurunnya pohon penghasil gaharu di alam sehingga menimbulkan kekhawatiran akan langkanya jenis ini. Dalam pertemuan The Conservation on the International Trade of Endangered species of Wild Flora (CITES) di Florida, Amerika Serikat tahun 1994 menyebutkan bahwa $A$. malacensis termasuk tumbuhan langka dengan status Appendix II. Penanaman jenis ini memerlukan dukungan penelitian, baik teknis pengadaan benih, pemeliharaan maupun penanamannya (Suhartono dan Mardiastuti, 2003).
Perkecambahan benih adalah pembiakan generatif suatu jenis pohon yang merupakan salah satu kegiatan budidaya tanaman untuk memproduksi anakan/bibit tanaman. Tulisan ini menjelaskan tentang daya kecambah selama satu peiode jatuhnya biji dari pohon induk dan penundaan perkecambahan biji dari jenis $A$. microcarpa.

Penelitian ini bertujuan untuk mendapatkan informasi tentang perkecambahan selama satu periode jatuhnya biji dari pohon induk dan daya kecambah dengan tertundanya perkecambahan biji A. microcarpa sehingga berguna dalam kelengkapan budidaya jenis tersebut di atas serta dapat menunjang program pembangunan hutan tanaman dan Gerakan Nasional Rehabilitasi Hutan dan Lahan (Gerhan) dengan jenis A. microcarpa di Kalimantan Timur.

\section{BAHAN DAN METODE}

\section{A. Lokasi, Waktu, Bahan, dan Alat Penelitian}

Penelitian dilakukan di Arboretum Sempaja dan Persemaian Balai Besar Penelitian Dipterokarpa di Samarinda, Kalimantan Timur. Penelitian dilaksanakan selama tiga bulan yaitu Desember 2004 hingga Februari 2005.

Bahan yang dipergunakan dalam penelitian ini adalah pohon induk jenis $A$. microcarpa yang sedang berbuah, sedangkan alat yang dipergunakan antara lain jaring perangkap biji atau sarlon, bak atau bedeng kecambah, sapu lidi, plastik, cangkul, parang, gergaji, palu, dan komputer. 


\section{B. Prosedur Penelitian}

\section{Prosedur Pengadaan Bahan Peneli- tian}

a. Penelitian dilakukan terhadap jenis $A$. microcarpa selama satu periode jatuhnya biji. Sebelum penelitian dilaksanakan, dilakukan survei dan pengamatan pohon induk yang sedang berbuah dari jenis tersebut di atas. Setelah ditemukan pohon induk yang sedang berbuah, selanjutnya memonitor buah-buah tersebut sejak buah masih muda hingga mulai masak.

b. Jika buah-buah tersebut sudah mulai masak selanjutnya dilakukan pemasangan jaring perangkap biji (seed trap) di bawah pohon induk tersebut, untuk menampung biji-biji yang jatuh.

c. Waktu pengumpulan biji yang jatuh ke dalam seed trap dilakukan sesuai dengan perlakuan interval waktu dalam metode penelitian ini.

d. Setiap waktu pengumpulan biji yang tertampung dalam seed trap, selesai dikumpulkan, berikutnya langsung dilakukan penyortian antara biji, serasah, kulit buah, dan benda lain yang jatuh bersama-sama biji ke dalam seed trap.

e. Setelah biji bersih dari benda-benda lain yang jatuh bersama-sama biji tersebut, tanpa menunda waktu biji tersebut langsung dikecambahkan dan berikutnya dilaksanakan pengamatan dan pengumpulan data hingga penelitian berakhir.

\section{Rancangan Penelitian}

Rancangan percobaan yang digunakan adalah Rancangan Acak Lengkap pola Faktorial 2 x 7 dengan tiga kali ulangan, tiap-tiap ulangan terdiri dari 30 biji.

Model yang digunakan adalah sebagai berikut (Hanafiah, 1991; Steel and Torrie, 1995):

$Y_{i j k}=\mu+\alpha_{i}+\beta_{j}+\succ_{k}+(\beta \succ)_{j k}+\varepsilon_{i j k}$

di mana:

$\mathrm{Y}_{\mathrm{ijk}} \quad=$ Respon variable yang diukur pada ulangan ke-i, media ke-j, interval waktu ke-k, interaksi media ke-j, dan interval waktu ke-k. $\mu \quad=$ Rata-rata (umum).

$\alpha_{\mathrm{i}} \quad=$ Efek ulangan ke-i.

$\beta_{\mathrm{j}} \quad=$ Efek media ke-j.

$\gamma_{\mathrm{k}}=$ Efek interval waktu ke-k

$(\beta \zeta)_{\mathrm{jk}}=$ Efek interaksi media ke-j, interval waktu ke-k.

$\varepsilon_{\mathrm{ijk}} \quad=$ Efek galat pada ulangan ke-i, media ke-j, interval waktu ke-k, interaksi media ke-j, dan interval waktu ke-k.

Faktor pertama perlakuan media kecambah terdiri dari dua taraf yaitu:

$\mathrm{E}_{0}=$ Media pasir tanpa endomikoriza.

$E_{1}=$ Media pasir dengan endomikoriza .

Sedangkan faktor yang kedua perlakuan interval waktu pengumpulan biji terdiri dari 7 faktor yaitu:

$\mathrm{P}_{1}=$ Pengumpulan biji hari ke-3.

$\mathrm{P}_{2}=$ Pengumpulan biji hari ke-5.

$\mathrm{P}_{3}=$ Pengumpulan biji hari ke-7.

$\mathrm{P}_{4}=$ Pengumpulan biji hari ke-10.

$\mathrm{P}_{5}=$ Pengumpulan biji hari ke-13.

$\mathrm{P}_{6}=$ Pengumpulan biji hari ke-17.

$\mathrm{P}_{7}=$ Pengumpulan biji hari ke-24.

Di samping penelitian tersebut dilaksanakan juga penelitian penundaan waktu pengecambahan biji. Sumber biji yang diteliti berasal dari biji yang dikumpulkan pada hari ke-7 atau biji yang dengan kualitas terbaik, sebab biji-biji yang dikumpulkan pada hari tersebut persentase kecambahnya paling banyak berkecambah.

Rancangan yang digunakan adalah Rancangan Acak Lengkap diulang tiga kali, tiap-tiap ulangan terdiri dari 30 biji dengan model sebagai berikut (Hanafiah, 1991; Steel and Torrie, 1995):

$Y_{i j}=\mu+\alpha_{i}+\beta_{j}+\varepsilon_{i j}$

di mana:

$Y_{i j}=$ Respon variable yang diukur pada ulangan ke-i, perlakuan ke-j.

$\mu \quad=$ Rata-rata (umum).

$\alpha_{i}=$ Efek ulangan ke-i.

$\beta_{\mathrm{j}}=$ Efek perlakuan ke-j.

$\varepsilon_{\mathrm{ij}}=$ Efek galat pada ulangan ke-i, perlakuan kej.

Perlakuan-perlakuan yang diterapkan adalah sebagai berikut:

$\mathrm{PW}_{0}=$ Biji langsung dikecambahakan.

$\mathrm{PW}_{1}=$ Pengecambahan biji tertunda 10 hari. 
$\mathrm{PW}_{2}=$ Pengecambahan biji tertunda 12 hari.

$\mathrm{PW}_{3}=$ Pengecambahan biji tertunda 17 hari.

\section{Pengumpulan dan Analisis Data}

Data yang dikumpulkan adalah daya kecambah biji dengan menggunakan rumus Direktorat Rebiosasi dan Rehabilitasi Lahan (1990) sebagai berikut:

$$
\begin{gathered}
\text { Daya } \\
\text { kecambah }
\end{gathered}=\frac{\begin{array}{c}
\text { Jumlah benih yang } \\
\text { berkecambah normal }
\end{array}}{\begin{array}{c}
\text { Jumlah benih yang } \\
\text { dikecambahkan }
\end{array}} \times 100 \%
$$

Data yang terkumpul dianalisis dengan uji F, yang berbeda nyata diuji lanjutan dengan Uji Beda Nyata Terkecil (BNT) (Hanafiah, 1991; Steel dan Torrie, 1995).

\section{HASIL DAN PEMBAHASAN}

\section{A. Satu Periode Jatuhnya Biji Dari Pohon Induk}

Hasil pengamatan menunjukkan bahwa selama satu periode jatuhnya biji dari pohon induk jenis $A$. microcarpa, memerlukan waktu 24 hari. Biji yang terkumpul selama penelitian setelah dikecambahkan sesuai dengan perlakuan seperti dalam metode penelitian (Gambar 1).

Gambar 1 menunjukkan bahwa ratarata daya kecambah biji jenis A. microcarpa selama satu periode jatuhnya biji dari pohon induknya secara keseluruhan sebanyak 74,76\%. Hal ini berarti bahwa biji dengan rata-rata daya kecambah $>74,76 \%$ termasuk biji yang berkualitas bagus dan biji dengan rata-rata daya kecambah $<74,76 \%$ tergolong biji berkualitas jelek.

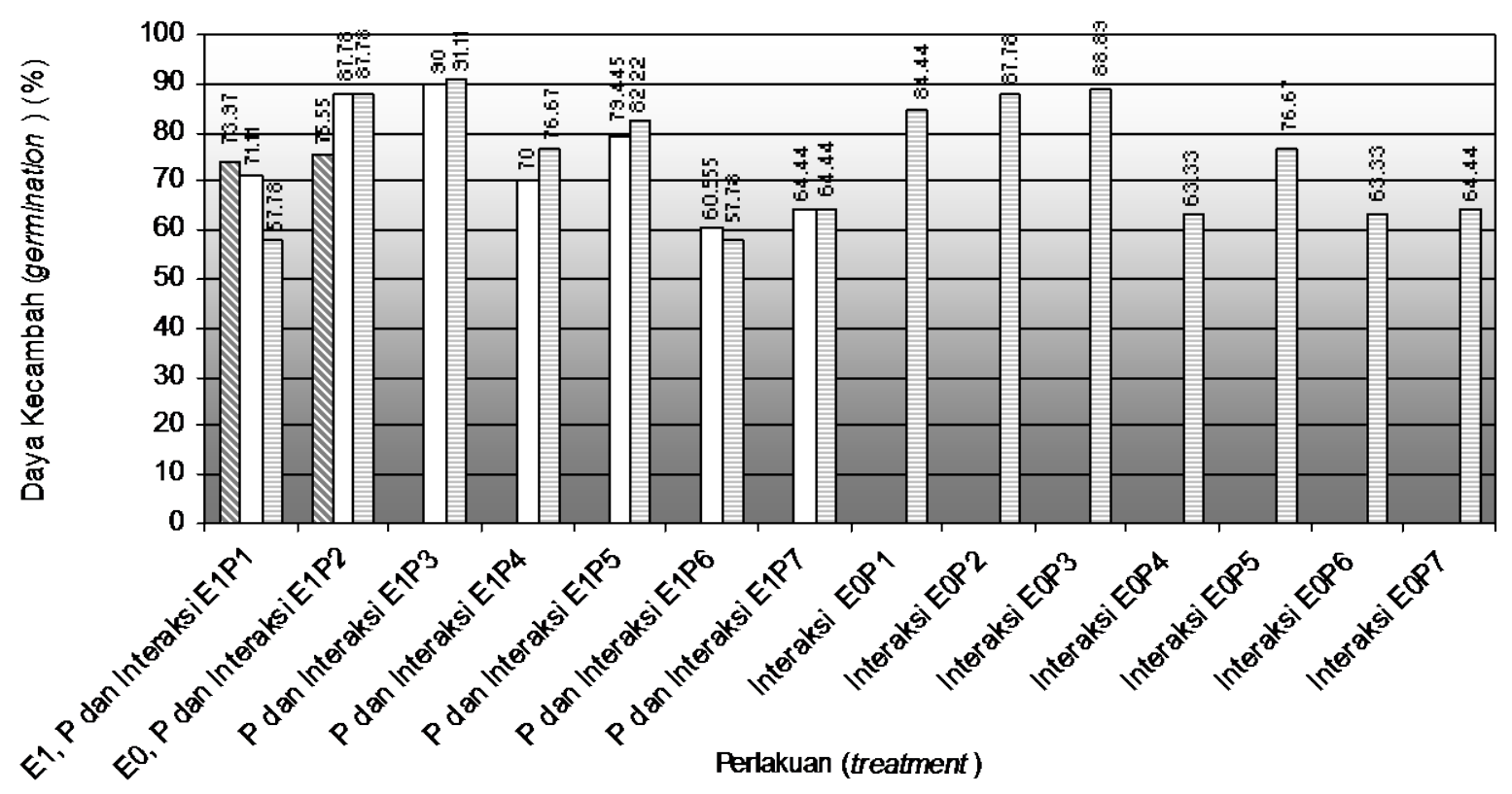

Keterangan (Remark):

$\mathbf{0}$ Pengaruh media (Media effect) (E);

$\square$ Pengaruh interval waktu (Time interval effect) (P);

四 Interaksi EP (EP interaction)

Gambar (Figure) 1. Daya kecambah biji A. microcarpa dengan perlakuan interval waktu jatuhnya biji dari pohon induk dan media ke-cambah pasir tanpa endomikoriza dan dengan endomikoriza (Seed germination rates of A. microcarpa with the treatments of collection time interval of seed fall from its mother trees and sand germinating media without and with endomycorrhiza) 
Dalam Lampiran 1 terlihat bahwa perlakuan yang diberikan berpengaruh sangat nyata. Pengaruh perlakuan yang sangat nyata tersebut adalah perlakuan interval waktu pengumpulan biji di bawah pohon induknya. Hal ini disebabkan karena secara fisiologis jatuhnya biji pada hari yang satu dengan hari lainnya kemungkinan mutunya berbeda sehingga menghasilkan daya kecambah yang berbeda pula. Sedangkan perlakuan media kecambah tidak berbeda nyata, begitu juga interaksi antara media kecambah dan interval waktu jatuhnya biji dari pohon induk. Hal ini disebabkan karena salah satu faktor yang menunjang berkecambahnya biji adalah kelembaban yang optimum, sedangkan media perkecambahan (pasir) yang diberi dan tanpa endomikoriza, apabila keduanya keadaan basah atau kering kelembabannya relatif sama sehingga tidak berpengaruh terhadap perkecambahan biji.

Hasil uji BNT (Lampiran 2) menunjukkan bahwa pengaruh perlakuan $\mathrm{P}_{6}$ (pengumpulan biji hari ke-17), $\mathrm{P}_{7}$ (pengumpulan biji hari ke-24), $\mathrm{P}_{5}$ (pengumpulan biji hari ke-13), dan $\mathrm{P}_{1}$ (pengumpulan biji hari ke-3) dengan daya kecambah berturut-turut $60,55 \%, 64,44 \%, \quad 70 \%$, dan $71,11 \%$, tidak berbeda nyata. Biji-biji yang jatuh pada hari-hari tersebut dikategorikan bermutu jelek, hal ini disebabkan karena biji-biji tersebut rata-rata daya ke- cambahnya lebih kecil dari rata-rata daya kecambah selama satu periode jatuhnya biji. Dalam penelitian ini rata-rata perkecambahan selama satu periode jatuhnya benih dari pohon induknya untuk jenis $A$. microcarpa adalah 74,76\%. Sedangkan perlakuan $\mathrm{P}_{4}$ (pengumpulan biji hari ke10) dengan daya kecambah $79,45 \%, \mathrm{P}_{2}$ (pengumpulan biji hari ke-5) daya kecambahnya $87,78 \%$, dan $\mathrm{P}_{3}$ (pengumpulan biji hari ke-7) menghasilkan daya kecambah 90\%. Perkecambahan tersebut dikategorikan berpredikat bagus atau baik, karena rata-rata daya kecambahnya lebih besar dari rata-rata daya kecambah selama satu periode jatuhnya biji (74,76\%). Berarti pengumpulan biji pada hari ke-10, ke-5, dan ke-7 dalam penelitian ini yang dapat menghasilkan biji bermutu baik sesuai dengan Sumarna (2003) yang menyebutkan bahwa perkecambahan benih dikategorikan baik bila tingkat partumbuhan kecambahnya mencapai 80 \%.

\section{B. Penundaan Pengecambahan}

Biji yang digunakan dalam penelitian penundaan pengecambahan adalah biji yang berkualitas paling baik yaitu biji yang dikumpulkan pada hari ke-7. Hasil rata-rata daya kecambah biji jenis $A$. microcarpa dengan perlakuan penundaan pengecambahan dapat dilihat pada Gambar 2 .

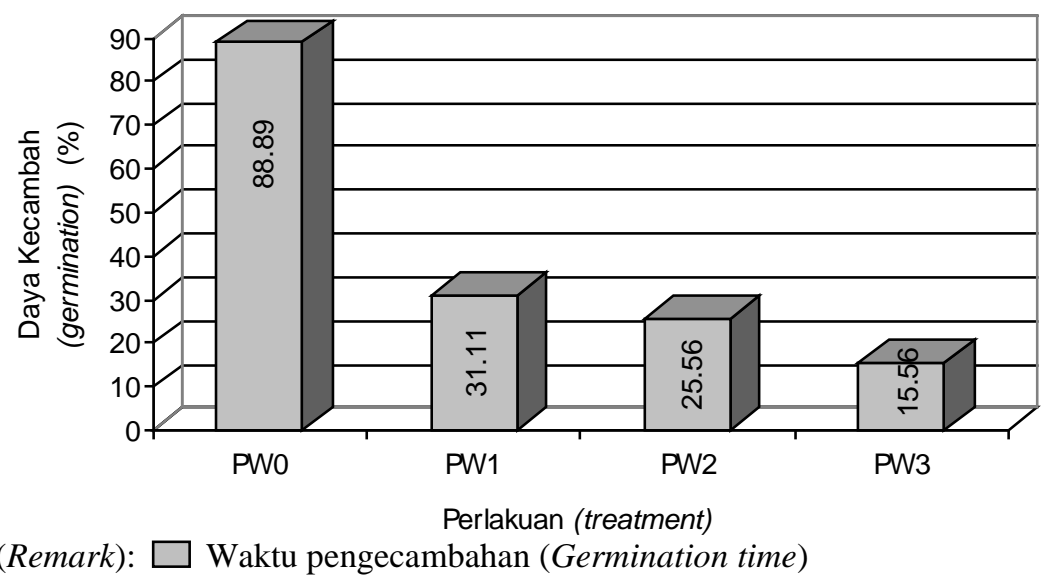

Keterangan (Remark): $\square$ Waktu pengecambahan (Germination time)

Gambar (Figure) 2. Rata-rata daya kecambah biji jenis A. microcarpa dengan perlakuan penundaan waktu pengecambahan di persemaian (Average seed germination rates of A. microcarpa with the treatment of the delay of seed germination at nursery) 
Gambar 2 menunjukkan bahwa ratarata daya kecambah biji jenis $A$. microcarpa dengan perlakuan penundaan pengecambahan sebesar 40,28\%, dikategorikan biji yang berkualitas jelek karena daya kecambahnya lebih kecil dibandingkan dengan rata-rata daya kecambah selama satu periode jatuhnya biji dari pohon induknya (74,76\%). Walaupun secara umum perlakuan ini menghasilkan ratarata daya kecambah biji berkualitas jelek, namun masih ada perlakuan yang menghasilkan rata-rata daya kecambah biji berkualitas baik yaitu perlakuan biji yang langsung dikecambahkan. Perlakuan ini menghasilkan daya kecambah lebih besar dari rata-rata daya kecambah selama satu periode jatuhnya biji dari pohon induknya yaitu $88,89 \%$.

Hasil analisis keragaman rataan daya kecambah biji jenis A. microcarpa dengan perlakuan penundaan pengecambahan (Lampiran 3) menunjukkan bahwa perlakuan yang diberikan terhadap daya kecambah biji berpengaruh sangat nyata.

Hasil uji BNT (Lampiran 4) menunjukkan bahwa perlakuan $\mathrm{PW}_{0}$ (langsung dikecambahkan) memberikan hasil terbaik karena berbeda nyata dengan perlakuan lainnya. Sedangkan perlakuan $\mathrm{PW}_{1}$ (penundaan waktu pengecambahan 10 hari), $\mathrm{PW}_{2}$ (penundaan waktu pengecambahan 12 hari), dan $\mathrm{PW}_{3}$ (penundaan waktu pengecambahan 17 hari) tidak berbeda nyata. Semakin lama penundaan waktu pengecambahan biji, semakin kecil daya kecambah yang dihasilkan.

\section{KESIMPULAN DAN SARAN}

\section{A. Kesimpulan}

1. Jenis Aquilaria microcarpa Baill. memerlukan waktu 24 hari untuk satu periode jatuhnya biji dari pohon indukya.

2. Daya kecambah tertinggi dicapai oleh biji-biji yang dikumpulkan pada hari ke-7 dengan daya kecambah 90\% dan yang terendah dicapai biji-biji yang dikumpulkan pada hari ke-17 dengan daya kecambah 60,55\%.
3. Rata-rata daya kecambah jenis A. microcarpa selama satu periode jatuhnya biji dari pohon induk sebesar 74,76\%.

\section{B. Saran}

Untuk memproduksi anakan jenis $A$. microcarpa Baill. dengan pembiakan generatif melalui biji disarankan agar pengumpulan biji dilaksanakan pada hari ke-5 hingga hari ke-10 jatuhnya biji dari pohon induknya dan tidak menunda-nunda waktu pengecambahan.

\section{DAFTAR PUSTAKA}

Direktorat Reboisasi dan Rehabilitasi Lahan. 1990. Perlakuan Pendahuluan Benih Cendana (Santalum album Linn) dengan Air $\left(\mathrm{H}_{2} \mathrm{O}\right)$, Asam Giberelin $\left(\mathrm{GA}_{3}\right)$, dan Asam Sulfat $\left(\mathrm{H}_{2} \mathrm{SO}_{4}\right)$. Tidak Diterbitkan.

Hanafiah, K. A. 1991. Rancangan Percobaan. Teori dan Aplikasi. Fakultas Pertanian Universitas Sriwijaya, Palembang.

Heyne, K. 1987. Tumbuhan Berguna Indonesia. Jilid III. Badan Litbang Kehutanan, Jakarta.

Schuitemaker, J. P. 1988. Kayu Gaharu dari Kalimantan Barat. Seri Himpunan Penulisan yang Berserakan. Terjemahan A. Azis Lahiya. Bandung.

Sidiyasa, K. dan M. Suharti. 1987. Jenis Tumbuhan Penghasil Gaharu. Prosiding Diskusi Pemanfaatan Kayu Kurang Dikenal. Cisarua, 13-14 Januari 1987. Badan Penelitian dan Pengembangan Kehutanan, Jakarta.

Steel, R.G.D and J. H. Torrie. 1995. Prinsip dan Prosedur Statistik: Suatu Pendekatan Biometrik. Penerbit PT Gramedia Pustaka Utama, Jakarta.

Suhartono, T. dan A. Mardiastuti. 2003. Perdagangan Gaharu. Pelaksanaan Konvensi CITES di Indonesia.

Sumarna, Y. 2003. Budidaya Gaharu. Seri Agribisnis. Penebar Swadaya, Bogor.

Tantra, I G. M. 1981. Flora Pohon Indonesia. Balai Penelitian Hutan, Bogor. Tidak diterbitkan. 
Lampiran (Appendix)1. Hasil uji beda nyata rata-rata daya kecambah biji jenis A. microcarpa dengan perlakuan interval waktu pengumpulan biji dan media kecambah dengan dan tanpa endomikoriza (Analysis of variance of the seed germination rate average of $\mathrm{A}$. microcarpa with the treatments of collection time interval of seed fall from its mother trees and sand germinating media without and with endomycorrhiza)

\begin{tabular}{lcccccc}
\hline \multicolumn{1}{c}{$\begin{array}{c}\text { Sumber keragaman } \\
\text { (Source of variation) }\end{array}$} & $\mathrm{db}$ & $\mathrm{JK}$ & $\mathrm{KT}$ & $\mathrm{F}_{\text {hit }}$ & \multicolumn{2}{c}{$\mathrm{F}$ tabel (F table) } \\
\cline { 6 - 8 } & $\mathrm{df}$ & $\mathrm{SS}$ & $\mathrm{MS}$ & $\mathrm{F}_{\text {cal }}$ & 0,05 & 0,01 \\
\hline Ulangan (Replication) & 2 & 347,62 & 173,81 & $1,56 \mathrm{~ns}$ & 2,37 & 5,53 \\
Perlakuan (Treatment): & 13 & 6040,21 & 464,63 & $4,16^{* *}$ & 2,125 & 2,91 \\
o perlakuan media (media treatment) (E) & 1 & 23,48 & 23,48 & $0,21 \mathrm{~ns}$ & 4,22 & 7,72 \\
o perlakuan waktu (time treatment) (P) & 6 & 4604,03 & 767,34 & $6,87 * *$ & 2,47 & 3,59 \\
o interaksi (interaction) (EP) & 6 & 1412,71 & 235,45 & $2,12 \mathrm{~ns}$ & 2,47 & 3,59 \\
Galat (Experimental error) & 26 & 2904,23 & 111,70 & & & \\
\hline Total (Total) & 41 & 9292,06 & & & &
\end{tabular}

Keterangan (Remark):

** = berbeda sangat nyata (highly significantly different); ns = tidak berbeda nyata (not significantly different)

Lampiran (Appendix) 2. Hasil uji beda nyata terkecil (BNT) rata-rata daya kecambah biji jenis A. microcarpa dengan perlakuan media kecambah dan interval waktu pengumpulan biji selama satu periode jatuhnya biji dari pohon induknya (Result of Least Significant Difference/LSD test of seed germination rate average of A. microcarpa with the treatments of germinating media and collection time interval of seed fall from its mother trees)

\begin{tabular}{cccc}
\hline $\begin{array}{c}\text { Pengaruh tunggal interval waktu } \\
\text { (Just one effect of time interval) }\end{array}$ & $\begin{array}{c}\text { Pengaruh tunggal media } \\
\text { (Just one effect of media) }\end{array}$ & $\begin{array}{c}\text { Pengaruh utama interval waktu } \\
\text { (Main effect of time interval) }\end{array}$ \\
\cline { 2 - 3 } & $\mathrm{E}_{0}$ & $\mathrm{E}_{1}$ & (M1,11abc \\
$\mathrm{P}_{1}$ & $87,78 \mathrm{a}$ & $84,44 \mathrm{bcd}$ & 87,78cd \\
$\mathrm{P}_{2}$ & $91,11 \mathrm{~d}$ & $87,78 \mathrm{~cd}$ & $98,89 \mathrm{~d}$ \\
$\mathrm{P}_{3}$ & $76,67 \mathrm{abcd}$ & $63,33 \mathrm{ab}$ & $70 \mathrm{ab}$ \\
$\mathrm{P}_{4}$ & $82,22 \mathrm{bcd}$ & $76,67 \mathrm{abcd}$ & $79,45 \mathrm{bcd}$ \\
$\mathrm{P}_{5}$ & $57,78 \mathrm{a}$ & $63,33 \mathrm{ab}$ & $60,55 \mathrm{a}$ \\
$\mathrm{P}_{6}$ & $64,44 \mathrm{abc}$ & $64,44 \mathrm{abc}$ & $64,44 \mathrm{ab}$ \\
$\mathrm{P}_{7}$ & $73,97 \mathrm{a}$ & $75,56 \mathrm{a}$ & \\
\hline
\end{tabular}

Keterangan (Remark):

Nilai yang mempunyai huruf yang sama tidak berbeda nyata pada taraf $1 \%$ (The values with the same letter are not significantly different at 1\%)

Lampiran (Appendix) 3. Hasil uji beda nyata rata-rata daya kecambah biji jenis A. microcarpa dengan perlakuan penundaan waktu pengecambahan di persemaian (Analysis of variance of seed germination rate average of A. microcarpa with the treatment of delay of seed germination at nursery)

\begin{tabular}{|c|c|c|c|c|c|c|}
\hline \multirow{2}{*}{$\begin{array}{c}\text { Sumber keragaman } \\
\text { (Source of variation) }\end{array}$} & \multirow{2}{*}{$\begin{array}{l}\mathrm{db} \\
d f\end{array}$} & \multirow{2}{*}{$\begin{array}{l}\mathrm{JK} \\
S S\end{array}$} & \multirow{2}{*}{$\begin{array}{l}\mathrm{KT} \\
M S\end{array}$} & \multirow{2}{*}{$\begin{array}{l}F_{\text {hit }} \\
\mathrm{F}_{\text {cal }} \\
\end{array}$} & \multicolumn{2}{|c|}{ F tabel (F table) } \\
\hline & & & & & 0.5 & 0.1 \\
\hline Perlakuan (Treatment) & 3 & 9825 & 3275 & $36,46 * *$ & 4,07 & 7,59 \\
\hline Galat (Experimental error) & 8 & 718,52 & 89,815 & & & \\
\hline Total (Total) & 11 & 10543,52 & & & & \\
\hline
\end{tabular}

Keterangan (Remark): ** = berbeda sangat nyata (highly significantly different) 
Lampiran (Appendix) 4. Hasil uji beda nyata terkecil (BNT) rata-rata daya kecambah biji jenis A. microcarpa dengan perlakuan penundaan waktu pengecambahan di persemaian (Result of Least Significant Differentce/LSD test of seed germination rate average of A. microcarpa with the treatment of delay of seed germination at nursery)

\begin{tabular}{ccc}
\hline Perlakuan (Treatment) & $\begin{array}{c}\text { Rataan daya kecambah (average of germination) } \\
(\%)\end{array}$ & BNT (LSD) (0.01) \\
\hline $\mathrm{PW}_{0}$ & 88,89 & $\mathrm{a}$ \\
$\mathrm{PW}_{1}$ & 31,11 & $\mathrm{~b}$ \\
$\mathrm{PW}_{2}$ & 25,56 & $\mathrm{~b}$ \\
$\mathrm{PW}_{3}$ & 15,256 & $\mathrm{~b}$ \\
\hline
\end{tabular}

Keterangan (Remark):

Nilai yang mempunyai huruf yang sama tidak berbeda nyata pada taraf $1 \%$ (The values with the same letter are not significantly different at $1 \%$ ) 